\title{
Using social knowledge networking technology to enable meaningful use of electronic health record technology in hospitals and health systems
}

\author{
Pavani Rangachari \\ Department of Health Management \& Informatics, Georgia Regents University, Augusta, United States
}

Correspondence: Pavani Rangachari. Address: Department of Health Management \& Informatics, College of Allied Health Sciences, Georgia Regents University, Augusta, GA 30912, United States. E-mail: prangachari@gru.edu

Received: August 4, 2014

DOI : $10.5430 /$ jha.v3n6p66

Accepted: September 19, 2014

URL: http://dx.doi.org/10.5430/jha.v3n6p66

Online Published: September 24, 2014

\section{Abstract}

Despite the federal policy momentum towards "meaningful use" of Electronic Health Records (EHRs), the healthcare organizational literature remains replete with reports of unintended adverse consequences of implementing EHRs, including: increased work for clinicians, unfavorable workflow changes, and unexpected changes in communication patterns \& practices. In addition to being costly and unsafe, these unintended adverse consequences may pose a formidable barrier to "meaningful use" of EHRs. Correspondingly, it is essential for hospital administrators to understand and detect the causes of unintended adverse consequences, to ensure successful implementation of EHRs. The longstanding Technology-in-Practice framework emphasizes the role of human agency in enacting structures of technology use or “technologies-in-practice”. Given a set of unintended adverse consequences from health information technology implementation, this framework could help trace them back to specific actions (types of technology-in-practice) and institutional conditions (social structures). On the other hand, the more recent Knowledge-in-Practice framework helps understand how information and communication technologies (e.g., social knowledge networking systems) could be implemented alongside existing technology systems, to create new social structures, generate new knowledge-in-practice, and transform technology-in-practice. Therefore, integrating the two literature streams could serve the dual purpose of understanding and overcoming unintended adverse consequences of EHR implementation. This paper seeks to: (1) review the theoretical literatures on technology use \& implementation, and identify a framework for understanding \& overcoming unintended adverse consequences of implementing EHRs; (2) outline a broad project proposal to test the applicability of the framework in enabling "meaningful use" of EHRs in a healthcare context; and (3) identify strategies for successful implementation of EHRs in hospitals \& health systems, based on the literature review and application.

\section{Key words}

Hospital administration, Electronic health records, Meaningful use, Information and communication technologies, Knowledge management, Change implementation

\section{I ntroduction}

The 2009 Health Information Technology for Economic and Clinical Health (HITECH) Act provides incentive payments to hospitals and healthcare providers, who adopt, implement, or demonstrate "meaningful use" of certified Electronic 
Health Record (EHR) technology. "Meaningful use” refers to use of certified EHR technology to improve the quality, safety, and efficiency of healthcare delivery, improve care coordination, engage patients and families in care delivery, and reduce healthcare disparities. Correspondingly, the meaningful use of EHR is said to offer the dual benefit of improved quality/patient outcomes and increased practice efficiencies/cost savings ${ }^{[1-4]}$. In addition, healthcare providers who demonstrate that they are using EHR in a meaningful way may qualify for significant federal financial incentives. As of August 2012, 54 percent of the Medicare- and Medicaid-eligible professionals had registered for the meaningful use incentive program ${ }^{[5]}$.

Despite the policy impetus towards meaningful use however, the healthcare organizational literature remains replete with reports of Unintended Adverse Consequences (UACs) of implementing EHRs. UACs refer to unanticipated and undesired effects of implementing EHRs. For example, some of the common UACs of EHR implementation include: increased work for clinicians, unfavorable workflow changes, ongoing demands for system changes, and conflicts between electronic and paper-based systems ${ }^{[6-10]}$. UACs could also result in unfavorable changes in communication patterns and practices and foster negative user emotions when physicians and other caregivers become frustrated with hard-to-use software. In addition, UACs could generate new kinds of errors, and lead to overdependence on technology that only comes to light when the system goes down. For example, physicians dependent on clinical decision support systems may have trouble recalling standard dosages or formulary recommendations. In summary, UACs could pose a formidable barrier to "meaningful use" of EHRs and health information technology (health IT), in general. Additionally, if left undetected, UACs could lead to errors endangering patient safety \& quality of care, and even to fraud and abuse, resulting in serious legal implications ${ }^{[11]}$. Therefore, it is essential for hospital administrators to detect and understand causes of UACs of EHR implementation, and strive to overcome UACs, to enable meaningful use of EHR technology.

To this effect, an evolving stream of industry literature on health IT use and implementation has begun outlining tools \& techniques for detecting causes of UACs ${ }^{[5,12-15]}$. Additionally, a comprehensive review of the theoretical literature suggests that integrating two streams of literature on "Technology-in-Practice" and "Knowledge-in-Practice" could provide a solid foundation not only for understanding causes of UACs from EHR implementation; but also for gaining insights into strategies to overcome them. Correspondingly, this purpose has a threefold purpose:

- To review the theoretical literature on technology use \& implementation, and identify a framework for understanding and overcoming UACs of EHR implementation;

- To outline a broad project proposal to test the applicability of the framework in enabling "meaningful use" of EHRs in a healthcare context;

- To identify strategies for successful EHR implementation, as well as implications for future research, based on the literature review and real-world application.

\section{Literature review and theoretical framework}

\subsection{Unintended adverse consequences of health IT implementation}

Previous research by Campbell et al. ${ }^{[8]}$ has served to provide a framework for characterizing and categorizing UACs from EHR/health IT implementation. Essentially, the study identified nine categories of UACs, including: (1) more/new work for clinicians; (2) unfavorable workflow issues; (3) never ending demands for system changes; (4) conflicts between electronic and paper-based systems; (5) unfavorable changes in communication patterns and practices; (6) negative user emotions; (7) generation of new kinds of errors; (8) unexpected changes in the power structure; and (9) overdependence on technology. Examples of UACs within each category are provided below.

Examples of unintended adverse consequences from health IT implementation: 
- More work for clinicians. Example: After the introduction of an EHR, physicians often have to spend more time on documentation because they are required to (and facilitated to) provide more and more detailed information than with a paper chart. While this information may be helpful, the process of entering the information may be time consuming, especially at first.

- Unfavorable workflow changes. Example: The EHR automates the medication and test ordering process by reducing the number of clinicians and clerical staff involved, but by doing so it also eliminates checks and counterchecks in the manual ordering process. That is, with the older system, nurses or clerks may have noticed errors, whereas now the order goes directly from the physician to the pharmacy or lab.

- Never-ending demands for system changes. Example: As EHRs evolve, users rely more heavily on the software, and demand more sophisticated functionality and new features (e.g., custom order sets). The addition of new functionalities necessitates that more resources be devoted to EHR implementation and maintenance.

- Conflicts between electronic and paper-based systems. Example: Physicians who prefer paper records annotate printouts and place these in patient charts as formal documentation, thus creating two distinct and sometimes conflicting medical records.

- Unfavorable changes in communication patterns and practices. Example: EHRs create an "illusion of communication”, (i.e., a belief that simply entering an order ensures that others will see it and act upon it.) For example, a physician fails to speak with a nurse about administering a medication, assuming that the nurse will see the note in the EHR and act upon it.

- $\quad$ Negative user emotions. Example: Physicians become frustrated with hard-to-use software.

- Generation of new kinds of errors. Example: Busy physicians enter data in a miscellaneous section, rather than in the intended location. Improper placement can cause confusion, duplication, and even medical error.

- Unexpected and unintended changes in institutional power structure. Example: IT, quality assurance departments, and hospital administration gain power by requiring physicians to comply with EHR-based directives (e.g., clinical decision support alerts).

- Overdependence on technology. Example: Physicians dependent on clinical decision support may have trouble remembering standard dosages, formulary recommendations, and medication contraindications during system downtimes.

\subsection{Understanding and detecting the causes of unintended adverse consequences}

Recent industry literature has suggested that the "Interactive Socio-technical Analysis (ISTA) framework" may be a useful framework for understanding the complex interactions that lead to unintended consequences ${ }^{[5]}$. The ISTA framework has four key elements: (1) The EHR (as designed), or how the developers envisioned that the EHR would be used; (2) The work environment: The policies, priorities, hierarchies, and relationships within the organization; (3) The technical and physical infrastructure: Other IT, medical devices, building design and layout; and (4) The EHR (as used): The product of interactions between the EHR and the work environment and the physical and technical infrastructure. The ISTA framework has been used to construct "cause and effect" diagrams to detect root causes of UACs ${ }^{[9]}$. Overall, the ISTA framework emanates from the belief that UACs of EHR implementation are the result of interactions between the EHR and other components of the work environment and infrastructure. However, while the ISTA framework recognizes the potential conflict between the design and use of EHRs, it is limited in its ability to explain "technology use" which is essential for developing interventions for impacting individual action in an organizational context. Along these lines, a focus on understanding technology use (or technology-in-practice) would be more relevant for hospital/health system administrators, compared to technology design, since healthcare managers are limited in their ability to impact IT design. 
The longstanding theoretical literature on technology-in-practice (TIP), delves deeper into the role of "technology use", to provide additional insights into understanding the causes of UACs in HIT implementation. The TIP literature suggests that when humans interact regularly with a technology, they engage with some or all of the material properties of the technology. The resulting recurrent social practice produces and reproduces a particular structure of technology use. These structures of technology use (or technologies-in-practice) are constituted recursively, as humans regularly interact with certain properties of a technology and thus shape the set of rules that serve to shape their interaction ${ }^{[16-18]}$.

Seen through this "practice lens", technology structures are emergent, not embodied. Rather than starting with the technology and examining how actors appropriate its embodied structures, this view starts with human action and examines how it enacts emergent structures through recurrent interactions with the technology at hand. Because the enactment of technology-in-practice is situated within a number of nested and overlapping social systems, people's interaction with technologies will always enact other social structures along with the technology-in-practice. For example, a hierarchical authority structure within a large bureaucracy, a cooperative culture within a participative workgroup, the normative structure of a religious or professional community.

The TIP framework helps understand the types of technologies-in-practice likely to be enacted under various institutional conditions (or social structures). As such, it serves as a useful framework for identifying causes of unintended consequences of technology implementation. For example, researchers have used the TIP lens in consulting companies to trace back unintended adverse consequences to "limited-use-technology-in-practice" and hierarchical network structures; and in software engineering companies, to trace back unintended favorable consequences, to "collective-problem-solvingtechnology-in-practice”, and collaborative network structures. Furthermore, TIP researchers have distinguished between "individual-productivity-technology-in-practice”, process-improvement-technology-in-practice”, and "improvisationtechnology-in-practice” ${ }^{[16,17]}$. In summary, based on evidence gathered across a variety of work contexts, TIP researchers have developed a framework for understanding the types of technologies-in-practice likely to be enacted under various institutional conditions (social structures). The table summarizes the "TIP Framework".

The table suggests that given a set of UACs from health IT implementation, the TIP framework can help trace them back to specific actions (types of technology-in-practice) and institutional conditions (social structures). Along these lines, applying the TIP lens to the research by Campbell et al. ${ }^{[8]}$ discussed earlier, suggests that a majority of UAC categories may be viewed as consequences of the enactment of a "limited use EHR-in-practice" by clinicians. For example, the specific challenges described under "more new work for clinicians"; "negative emotions" and "unexpected changes in the power structure", suggests a general distrust of administration's motives, among clinicians in the study facilities. The challenges described under "unfavorable workflow issues", "generation of new types of errors", and "untoward changes to communication patterns”, suggest skepticism among clinicians in regard to the EHR system's ability to improve patient safety. For example, it has been well documented that clinicians complain about unsatisfactory reductions in face-toface communications and excessive use of standardized terminology. These issues suggest a general perception that EHR creates dysfunctional workflows and disrupts beneficial team communication. Consequently, clinicians react by attempting to preserve existing practices and work roles. Last but not least, the problems described under "never-ending demands for system changes", and "overdependence on technology", suggest a sense of fear and denial about ongoing changes in work practices due to new technology. They also indicate computer anxiety, fear of deskilling, and desire for professional autonomy. To summarize, clinicians draw upon the "hierarchical social structure", their limited knowledge of EHRs, their orientation to patient care and established roles/processes, to enact a set of minimal rules and resources which barely influence their existing work practices. In turn, this "limited use EHR-in-practice”, because it provided them with little value, strengthens clinicians' assumptions about EHRs as less than useful for patient care delivery, and reinforces their orientation to existing practices. 
Table. The TIP framework which links actions, conditions, and consequences (Resolution: > 300 dpi).

\begin{tabular}{|c|c|c|c|c|c|c|c|}
\hline \multicolumn{2}{|c|}{ ACTIONS } & \multicolumn{3}{|c|}{ CONDITIONS } & \multicolumn{3}{|c|}{ CONSEQUENCES } \\
\hline $\begin{array}{l}\text { Technology- } \\
\text { in-practice }\end{array}$ & $\begin{array}{l}\text { Type of } \\
\text { Enactment }\end{array}$ & $\begin{array}{l}\text { Interest in Using } \\
\text { Technology }\end{array}$ & $\begin{array}{l}\text { Interpretive } \\
\text { Conditions }\end{array}$ & $\begin{array}{l}\text { Institutional } \\
\text { Conditions }\end{array}$ & $\begin{array}{l}\text { Process-Related } \\
\text { Consequences }\end{array}$ & $\begin{array}{l}\text { Technological } \\
\text { Consequences }\end{array}$ & $\begin{array}{l}\text { Structural } \\
\text { Consequences }\end{array}$ \\
\hline Limited-Use & Inertia & Low & $\begin{array}{l}\text { Limited } \\
\text { technical } \\
\text { knowledge }\end{array}$ & $\begin{array}{l}\text { Hierarchical, } \\
\text { Individualistic, } \\
\text { Competitive }\end{array}$ & None & None & $\begin{array}{l}\text { Reinforce and } \\
\text { preserve status } \\
\text { quo }\end{array}$ \\
\hline $\begin{array}{l}\text { Individual-Pro } \\
\text { ductivity }\end{array}$ & Application & Moderate & $\begin{array}{l}\text { Moderate } \\
\text { technical } \\
\text { knowledge }\end{array}$ & $\begin{array}{l}\text { Hierarchical, } \\
\text { Individualistic, } \\
\text { Competitive }\end{array}$ & $\begin{array}{l}\text { Increased efficiency } \\
\text { in communication }\end{array}$ & $\begin{array}{l}\text { Changes to the } \\
\text { data }\end{array}$ & $\begin{array}{l}\text { Reinforce and } \\
\text { enhance status } \\
\text { quo }\end{array}$ \\
\hline $\begin{array}{l}\text { Collective-Pro } \\
\text { blem-Solving }\end{array}$ & Application & High & $\begin{array}{l}\text { Detailed } \\
\text { technical } \\
\text { knowledge }\end{array}$ & $\begin{array}{l}\text { Communal, } \\
\text { Cooperative }\end{array}$ & $\begin{array}{l}\text { Increased } \\
\text { effectiveness in } \\
\text { problem-solving; } \\
\text { Increased } \\
\text { cooperation }\end{array}$ & $\begin{array}{l}\text { Adaptations to } \\
\text { the tool; } \\
\text { Changes to the } \\
\text { data }\end{array}$ & $\begin{array}{l}\text { Reinforce and } \\
\text { enhance status } \\
\text { quo }\end{array}$ \\
\hline $\begin{array}{l}\text { Process- } \\
\text { Support }\end{array}$ & Application & Very High & $\begin{array}{l}\text { Competent } \\
\text { technical } \\
\text { knowledge }\end{array}$ & $\begin{array}{l}\text { Team-focused, } \\
\text { Cooperative, } \\
\text { Learning } \\
\text { Oriented }\end{array}$ & $\begin{array}{l}\text { Increased } \\
\text { effectiveness in } \\
\text { customer service; } \\
\text { Increased efficiency } \\
\text { in communication }\end{array}$ & $\begin{array}{l}\text { Adjustments in } \\
\text { the tool; } \\
\text { Changes to the } \\
\text { data }\end{array}$ & $\begin{array}{l}\text { Reinforce and } \\
\text { enhance status } \\
\text { quo }\end{array}$ \\
\hline Improvisation & Change & High & $\begin{array}{l}\text { Competent } \\
\text { technical } \\
\text { knowledge }\end{array}$ & $\begin{array}{l}\text { Team-focused, } \\
\text { Collaborative, } \\
\text { Learning } \\
\text { Oriented }\end{array}$ & $\begin{array}{l}\text { Redefined work } \\
\text { distribution; Shift in } \\
\text { type of collaboration; } \\
\text { Change in ways of } \\
\text { learning }\end{array}$ & $\begin{array}{l}\text { Adaptations to } \\
\text { the tool; } \\
\text { Changes to the } \\
\text { data }\end{array}$ & $\begin{array}{l}\text { Transform } \\
\text { status quo }\end{array}$ \\
\hline
\end{tabular}

A key limitation of the TIP literature however, is that while it helps understand causes of unintended consequences of technology implementation, it does not by itself provide solutions to overcome them. A more recent stream of literature on knowledge-in-practice (KIP), which emanates from the broader literature stream on implementing and sustaining change in healthcare organizations has sought to understand how the creation of new communication (network) structures (or social structures) could enable the creation of new knowledge to in turn facilitate collective learning and organizational change ${ }^{[19-27]}$.

In recent years, the KIP literature has focused on understanding which types of information and communication technologies may be most effective for activating different types of knowledge ${ }^{[28-32]}$. This research suggests that explicit knowledge (i.e., formal knowledge) may be best activated through intranets and "Virtual Offices" which create open shared spaces; whereas, tacit knowledge (i.e., knowledge embedded in practices, and essential for problem solving \& innovation), may be best activated through information and communication technologies such as social knowledge networking (SKN) systems, which have the potential to enable reciprocal interaction and relationships.

The figure depicts the associations between types of information \& communication technologies, network structures, knowledge activated, and the collective goal (e.g., "problem-solving” or "innovation”). In effect, the figure summarizes the KIP framework, which provides insights into strategies for using information and communication technologies to transform social structures and create new knowledge (to enable collective learning and change). Therefore, integrating the KIP framework with the TIP framework would suggest that implementing SKN systems alongside existing health IT systems (e.g., EHRs) could help transform technologies-in-practice by creating new social structures, and generating new knowledge- in-practice.

Recent literature has sought to integrate TIP and KIP frameworks to propose strategies for overcoming UACs from EHR implementation ${ }^{[33]}$. Based on the typologies provided in the table (TIP Framework) and the figure (KIP Framework), an integrated TIP/KIP framework would suggest that using SKN technology alongside an existing EHR system could help transform a "limited use-EHR-in-practice” to a "collective-problem-solving EHR-in practice”, by transforming social structures and creating new knowledge-in-practice to enable collective learning and change. 


\begin{tabular}{|c|c|c|c|}
\hline $\begin{array}{l}\text { Information and } \\
\text { Communication } \\
\text { Technology (ICT) }\end{array}$ & $\begin{array}{l}\text { Type of Knowledge Sharing } \\
\text { Structure Facilitated by ICT }\end{array}$ & $\begin{array}{c}\text { Type of } \\
\text { Knowledge } \\
\text { Activated by ICT }\end{array}$ & $\begin{array}{c}\text { Collective } \\
\text { (Organizational) } \\
\text { Purpose }\end{array}$ \\
\hline $\begin{array}{l}\text { Centrally coordinated } \\
\text { open shared spaces } \\
\text { similar to those offered } \\
\text { by web-based content } \\
\text { management } \\
\text { systems. }\end{array}$ & $\begin{array}{l}\text { Top-down } \\
\text { hierarchical structure } \\
\text { with minimal direct } \\
\text { communication } \\
\text { among peers and } \\
\text { across professional } \\
\text { subgroups. }\end{array}$ & $\begin{array}{l}\text { Explicit } \\
\text { Knowledge }\end{array}$ & $\begin{array}{l}\text { Product } \\
\text { Development }\end{array}$ \\
\hline $\begin{array}{l}\text { Facilitated closed spaces } \\
\text { similar to those offered by } \\
\text { moderated "forums" within } \\
\text { social knowledge networking } \\
\text { (SKN) systems, that are } \\
\text { dedicated to resolving specific } \\
\text { problems, with facilitators } \\
\text { setting rules of engagement. }\end{array}$ & $\begin{array}{l}\text { Direct } \\
\text { communication } \\
\text { across subgroups, } \\
\text { that is coordinated } \\
\text { and facilitated by } \\
\text { administrators. }\end{array}$ & $\begin{array}{l}\text { Tacit - } \\
\text { Discretionary } \\
\text { Knowledge }\end{array}$ & $\begin{array}{l}\text { Collective } \\
\text { Problem } \\
\text { solving }\end{array}$ \\
\hline $\begin{array}{l}\text { Cohesive closed spaces, similar } \\
\text { to those offered by "blogs" and } \\
\text { "web pages" within social } \\
\text { knowledge networking (SKN) } \\
\text { systems, which enable a free } \\
\text { exchange of ideas on various } \\
\text { topics of interest, with no } \\
\text { interference from authority. }\end{array}$ & $\begin{array}{l}\text { Frequent direct } \\
\text { communication } \\
\text { across subgroups } \\
\text { with free exchange } \\
\text { of ideas and } \\
\text { minimal interference } \\
\text { from authority } \\
\text { (administrators). }\end{array}$ & $\begin{array}{l}\text { Tacit - } \\
\text { Autonomous } \\
\text { Knowledge }\end{array}$ & Innovation \\
\hline
\end{tabular}

Figure. The KIP framework which links information and communication technologies with network structures and type of knowledge activated (Resolution: >300 dpi).

For example, "moderated discussion forums" within SKN systems could be used to enable top-down vetted content to be combined with bottom-up tacit knowledge. To this effect, forums organized around specific problems encountered during EHR implementation could help activate tacit knowledge required for collective problem solving. Examples of forum topics within SKN systems may include "practice guidelines validity”, “dysfunctional workflows" and "structured entry". For instance, the forum on "practice-guidelines validity" could be used by hospital administrators to communicate tacit knowledge related to (1) the growing importance of evidence-based guidelines for hospital accreditation; and (2) the true number of near-misses and adverse drug events encountered in pre-existing medication ordering systems. This type of knowledge sharing could in turn help create a "shared meaning" between hospital administrators and clinicians in regard to the value of the EHR system for patient safety and quality. Similarly, a forum on "dysfunctional workflows" may prompt clinicians (including generalist and specialist physicians) to establish a consensus regarding medication ordering. For example, physicians may decide that only the computer would be used to communicate orders and that if both verbal and computer orders occur, then the latter would supersede the former. This could help eliminate any miscommunication resulting in errors and waste. In a similar vein, a forum on "structured entry" could enable reciprocal interactions among clinicians, the IT department, and hospital administrators to enable collective problem solving. IT staff in turn, would have an opportunity to clarify the importance of using structured data entry for measurement purposes. They would also gain opportunities to enhance the effectiveness of training sessions so that clinicians can comprehend the consequences of not using the system in a timely fashion.

Therefore, the introduction of SKN technology alongside the existing EHR system could have the effect of transforming the existing "hierarchical" network structure into a "cooperative” one, to activate tacit knowledge for collective problem solving. The resulting new social structure, in turn, would have the effect of transforming a "limited-use-EHR-in-practice", into a "collective-problem-solving-EHR-in-practice". In a similar vein, the integrated TIP/KIP framework suggests that the use of "blogs" and "content repositories" (within SKN systems) to enable a free exchange of ideas (i.e., tacit knowledge), with no intervention from formal authority, could help transform a "limited-use-EHR-in-practice" into an "improvisation-EHR-in-practice" through. The overall takeaway from the integrated TIP/KIP framework is that information and communication technologies (e.g., SKN systems), could be implemented alongside existing EHR systems to transform EHR technology-in-practice from "limited use" to "meaningful use." 


\section{A broad project proposal to apply the integrated theoretical framework to a healthcare context}

To explore the potential applicability of the integrated TIP/KIP framework in enabling "meaningful use" of EHRs in a real-world context, let us consider a hospital/heath system, ABC Health, which recently launched certified EHR technology. As part of the EHR, healthcare providers may electronically prescribe medications through a system which enables them to view patients' medication history and prescriptions filled through participating pharmacies. Like many healthcare organizations, a key challenge faced by ABC Health is that providers (generalists and specialists) who did not originally order patient medications are resistant to reconciling medications on EHR at discharge, i.e., to "continuing” or "discontinuing" medications they did not order. The end results are frustrated patients with incomplete medication lists and discharge instructions, and higher-than-expected medication error rates. In 2013, the ABC Health averaged a monthly medication history intake rate of 36\% (upon patient arrival) and medication reconciliation rate of $17 \%$ (at discharge). During the same period, the average monthly patient satisfaction score related to medication instructions, i.e., "medications and care at home were explained to me in a way I could understand", was at the 44th percentile for outpatient clinic visits, 40th percentile for inpatient discharges, and 2nd percentile for the Emergency Department. Concurrently, national comparative data from the University Health Consortium (UHC) database revealed that ABC Health was at the 75th percentile for proportion of medication events causing patient harm (i.e., adverse drug events); with over $30 \%$ of the errors being attributed to patient-provider communication, a rate almost three times the national average. Medication errors are estimated to injure over one million people and cost billions of dollars each year ${ }^{[34,35]}$. Thus, the meaningful use of EHR medication reconciliation technology has the potential to dramatically improve patient safety, decrease healthcare costs, and engage patients \& families in care delivery ${ }^{[36-38]}$.

The TIP framework helps understand the types of technologies-in-practice likely to be enacted under various institutional conditions (social structures). Therefore, applying the TIP framework to the ABC Health context suggests a "limited-useEHR-in-practice" and a "hierarchical network structure". For example, the problem of physicians being resistant to continue/discontinue medications they did not originally order, suggests skepticism among clinicians in regard to the EHR system's ability to improve medication \& patient safety. It also suggests a "hierarchical network structure," including a lack of communication between health system administrators and clinicians in regard to: (1) prevailing "best practices" related to EHR medication reconciliation; (2) the changing roles of physicians, nurses, and pharmacists in implementing the process; and (3) the value and benefits of EHR medication reconciliation in reducing medication errors and improving patient care quality \& safety.

As a corollary to using the TIP framework to understand the causes of UACs at ABC Health; applying the integrated TIP/KIP framework to the ABC Health context would suggest that the health system could greatly benefit from implementing an SKN system alongside its existing EHR system, to transform the EHR-in-practice from "limited use" to "meaningful use”. In summary, ABC Health might greatly benefit from a Quality Improvement Intervention involving the implementation of SKN technology alongside the existing EHR system, to enable meaningful use of the EHR medication reconciliation system.

In keeping with this plan, an interdisciplinary team of "SKN Moderators" (including key administrators/managers and clinicians/practitioners) from within the health system will implement a web-based SKN system to enable meaningful use of EHR Medication Reconciliation Technology. The SKN system would allow approximately 100 participants from diverse professional subgroups (including primary care physicians, specialists, nurses, pharmacists, IT managers, and hospital administrators) from select clinics/units at ABC Health, to discuss "meta" (system-level) administrative, policy, and communication issues related to medication reconciliation, and exchange specialized knowledge to improve medication safety. Correspondingly, the SKN system would serve as a platform for interactive problem solving related to EHR medication reconciliation and collective learning related to medication safety and patient-centered care practices. 
The features of an SKN system would include: (1) Moderated discussion forums, for allowed users to comment on and respond to a particular problem or challenge; (2) Blogs and home pages, to generate ideas on a particular subject; and (3) Content repositories and sophisticated search capabilities. Presto ${ }^{\odot}$ offered by Inmagic Inc., is an example of an SKN system currently available on the market ${ }^{[39,40]}$. Presto ${ }^{\circ}$ is a web-based application that enables non-technical organizational users to create and manage social knowledge networks. It is available on a "subscription license", the cost of which is driven by the number of end-users.

Importantly, the EHR system by itself, offers no avenue for interactive problem solving or collective learning of medication safety best practices across provider groups. The only communication platform offered by the EHR is a "message center" for physicians to receive individual patient-related updates from nursing, radiology, pharmacy and the lab. For example, a patient on Warfarin therapy may complain to a nurse that his/her medication list is not up-to-date with removal of certain medications. However, the nurse may feel this change is outside the scope of his/her work and that the doctor must approve discontinuation of those medications, before they are removed. A doctor, who may not have originally ordered those medications, may refrain from discontinuing them. Such a situation could create negative consequences for patient satisfaction and patient safety; and these types of issues/problems cannot be addressed simply by using the EHR system.

Correspondingly, in the situation described above, the nurse in question may wish to access individual stories of patient suffering from failure to reconcile medications, to educate the doctor on associated risks. For example, the nurse may search the "content repositories" of the SKN system to locate a recent story of a patient (on anticoagulation therapy) who underwent liposuction, and subsequently hemorrhaged and died from failure to reconcile Warfarin medications. The nurse may in turn share this story with the doctor on a "moderated discussion forum" in the SKN system. Such a story in turn, could resonate with the doctor and help underscore the importance of consistently performing medication reconciliation in his/her practice, compared to a formal report of aggregate data on adverse drug events. On a related note, the same nurse may wish to find out "best practices", i.e., what some of the other clinics are doing to reconcile medications and communicate with Warfarin patients, so s/he in turn could share best practices with his/her peers. On another day, she/he may encounter a different problem of "rigidity" in a data entry field for Warfarin dosages, and may wish for more customizability in recording weekly dosing changes. While the EHR platform by itself may not be able to address such problems/issues, a web-based SKN application (easily accessible from the desktop or mobile devices) would provide the nurse with an opportunity to relay and discuss the data entry problem with information technology specialists in a dedicated "Warfarin forum". In summary, an SKN system, if implemented alongside an EHR system could provide a platform for interactive problem solving related to medication reconciliation and collective learning related to medication safety, within and across clinician and administrator subgroups.

A distinguishing feature of SKN technology is that it helps combine top-down vetted content with bottom-up social knowledge to address high-impact organizational challenges. Correspondingly, the team of "SKN moderators" at ABC Health would play a key role in engaging \& recruiting participants to the SKN system, and implementing forums and blogs to facilitate knowledge sharing and collective learning related to medication reconciliation and safety. Prior to participant recruitment, SKN Moderators will collect baseline data to lay a comprehensive foundation for the intervention. Baseline data will be collected at the clinic (unit) level on: (1) Process and Outcome Measures (e.g., the EHR Medication Reconciliation Rate, the Medication Error Rate, the Adverse Drug Event Rate, and Patient Satisfaction Score \& Percentile Ranking), and (2) Clinic Characteristics (e.g., specialization, size, and patient volume). Additionally, SKN moderators will administer a questionnaire among clinic (unit)-level practitioners to obtain baseline data on prevailing communication practices related to medication reconciliation. The questionnaire will obtain information on specific problems practitioners would like to address in regard to medication reconciliation. The questionnaire will also obtain information on prevailing areas of expertise among practitioners, and interest in participating in moderated discussion forums related to medication safety and patient-centered care delivery. 
Once study sites (i.e., intervention clinics/units within ABC Health) are identified, SKN Moderators will leverage baseline data from the questionnaire to engage and recruit participants to the SKN system. Participants will be informed that the SKN system would be responsive to their needs and that they would serve as partners in improving medication safety and promoting patient-centered care. The SKN moderators will undertake active and systematic efforts to engage the participant community in use of the SKN system. The baseline questionnaire data will be used to invite participants to specific forums and blogs; and all participants will receive regular emails alerting participants to new content on the SKN system and encouraging participation. Additionally, in-kind incentives in the forms of "gift cards" or compensation for travel related to education and/or professional development would be distributed to participants who contribute who make substantial contributions through the SKN system.

SKN Moderators will use baseline data from the questionnaire to conduct targeted interventions to promote meaningful use of EHR medication reconciliation. SKN Moderators will also provide ongoing feedback of data collected on process \& outcome measures, to enable process improvements at the clinic/unit-level. While targeted interventions from SKN Moderators would enable "top-down" problem identification, the social networking capabilities of the SKN system are expected to also enable bottom-up problem identification and problem resolution through tacit knowledge exchange. In short, the SKN system is expected to enable a knowledge community on medication safety to evolve organically.

The primary aim of this project would be to examine the relationship between use of SKN technology and meaningful use of EHR technology. The primary hypothesis is that use of SKN technology would transform EHR-in-practice from "limited use" to "meaningful use" by developing network structures for generating new knowledge-in-practice. Secondary hypotheses would pertain to use of specific features of SKN technology, i.e., (1) Use of "forums" within the SKN system would transform a "limited-use-EHR-in-practice" into a "collective-problem-solving-EHR-in-practice"; (2) Use of "blogs" would transform the "limited-use-EHR-in-practice" into an "improvisation-EHR-in-practice". A prospective and quasi-

experimental mixed-method design, incorporating quantitative analysis, network analysis, and content analysis, would be used to examine the relationship between SKN use and meaningful use of EHR.

In summary, such a project if implemented could help directly validate the applicability of the integrated TIP/KIP framework in enabling meaningful use of EHR technology in a real world scenario. The project would lay a foundation for understanding the role of SKN systems in enabling the meaningful use of EHR; and moreover, it would shed light on the mechanisms by which meaningful use occurs at the clinic (unit) level, including the communication \& knowledge sharing network structures that are associated with problem solving, collective learning, and practice change. These insights could in turn lay a foundation for generating "evidence-based management" strategies for meaningful use of EHR, including the optimal use of information and communication technologies and the design of organizational communication structures for enabling successful implementation of EHR at the frontlines of care (i.e., at the clinic/unit level).

Additionally, the study has potential to identify innovative strategies for clinician education \& provider engagement in the context of medication safety and patient-centered care delivery. Importantly, it would help delineate the changing role of hospital administrators in facilitating practice change. This would have direct implications for workforce literature, especially in regard to the mix of clinical and administrative professionals in care delivery. For example, it could help delineate the importance of a new breed of professionals in healthcare organizations; the SKN moderators - having the administrative and clinical savvies to improve information flow, bridge enterprise silos and address a broad family of organizational problems and challenges. The project would have equally strong potential to contribute to the patientcentered care literature, particularly on the role of information \& communication technologies in enabling patient-centered care. Such a project would also have broad policy implications. For example, if the hypothesis holds, federally certified EHR vendors could be encouraged to identify novel ways to incorporate SKN features within EHR systems. To this effect, having IT professionals as participants within the SKN system has the potential to stimulate ideas for achieving this 
purpose. Such results could also carry important implications for accreditation, wherein use of SKN in some form (for enabling meaningful use of EHR) could become an accreditation requirement for healthcare organizations.

\section{Discussion}

\subsection{I mplications for hospital administrators and strategies for successful EHR implementation}

A key contribution of the integrated TIP/KIP framework is that it can help hospital administrators with: (1) understanding the causes of UACs of health IT implementation; and (2) gaining insight into strategies for overcoming them through the use of information and communication technologies to transform EHR-in-practice. The integrated theoretical framework suggests that information and communication technologies can be leveraged to create new social structures, generate new knowledge-in-practice, and transform technology-in-practice. Additionally, the application of the theoretical framework to a real-world context by way of a broad project proposal suggests that efforts to modify social structures \& systems through use of information and communication technologies (such as SKN systems) may need to be championed by senior administrators and practitioners ("SKN Moderators"), who undertake proactive and ongoing efforts to engage \& educate individual clinicians in the use of the new SKN system, and thereby overcome barriers to technology acceptance at the individual clinician level. While the introduction of the SKN system by itself could impact EHR-in-practice, individual clinicians need to be motivated to participate in the new knowledge networks created by SKN system, and willingly part with their tacit-discretionary knowledge, to enable collective problem-solving and learning at the system level.

Another lesson learned from the literature is that knowledge is not homogeneous. The highly public nature of most tools for electronic collaboration overlooks this. Many organizations are known to build an open and generic forum for communication and assume that members of the targeted community will make use of this. Instead, the key challenge is to activate clinicians' knowledge through new communication network structures (or social structures). Correspondingly, managers must make proactive and ongoing efforts to: (1) increase the "perceived usefulness" of the new health IT system; (2) develop a solid infrastructure for ongoing training of clinicians; and (3) provide incentives for clinicians to learn the new technology, and share their tacit knowledge for collective problem solving.

In summary, the integrated TIP/KIP framework and its application to a real-world context by way of a broad project proposal, provide insight into various management strategies for the successful EHR implementation in a hospital setting, as outlined below:

\section{(1) Ensure the presence of dedicated and supportive leaders (i.e., champions for change)}

Securing financing approval from the Board of Directors and detailed business plans from key leaders (e.g., Chief Executive Officer, Chief Information Officer, Chief Nursing Officer, and Chief Medical Officer) is an essential precondition for successful implementation. At the same time, it is critical to develop a shared vision and organize for success. Administrative leadership throughout the organization must be involved and physician leadership must be active and engaged from the start.

\section{(2) Proactively communicate the value and benefits of using new technology}

Hospital administrators and leaders must communicate benefits of the EHR system to individual clinicians on a proactive and ongoing basis (like for example, by serving as "SKN Moderators" on the SKN system). They must highlight its value in terms of time, efficiency, and quality/safety, including the reduction of medical errors. They could also emphasize other benefits such as: standardized processes; standardized nursing documentation; availability of electronic health records to all care providers; improved auditing capabilities; "built-in” regulatory compliance; readily available reference information; and improved safety with legibility/accuracy. 


\section{(3) Design with physicians and nurses and listen to the users}

Hospital administrators and leaders must strive to develop a multidisciplinary \& collaborative design team. Physician and nursing input in design, testing, and education, can speed up training and adoption and also help utilize technology appropriately. More significantly, it can help avoid workarounds (which could end up underutilizing technology, overriding safety features and creating inconsistencies of care).

\section{(4) Engage clinicians; offer incentives; and create a supportive team culture}

Success stories in EHR implementation highlight the importance of identifying organizational-level project leaders from both "operations" and "IT" perspectives. Such leaders could be nurses or physicians with prior computer experience and time management skills. They must be comfortable with point-of-care documentation, and must be team players, open to change. These computer savvy "super-users" of the EHR system could be incentivized to work on EHR design and testing. Their efforts must be valued and rewarded, and their feedback used an ongoing basis to institute changes and improvements as needed.

\section{(5) Train the masses and set up for continuous technology evaluation, training, and improvement}

Successful EHR implementation requires time for user-paced learning, extensive practice, and consistent use. It is essential to recognize generational differences and plan training/education accordingly. It is important to make training sessions accessible to everyone, and to not assume that a particular person will not need training because of their job title. While flexibility in training may be a plus, it is critical to have an incentive system in place to encourage compliance. The best designs will be outdated quickly. As such, it is essential to be prepared for continuous system upgrades and newer technology. It is also important to prepare for ongoing workflow changes, as users begin to share knowledge on the SKN system, to solve problems and improvise with respect to using the EHR system.

\subsection{I mplications for future research}

The integrated (TIP/KIP) framework and its application provide insight into several avenues for EHR implementation research. To begin with, exploratory studies similar to the broad project proposal may be undertaken to examine the effect of using information and communication technologies (such as SKN systems) alongside new or existing EHR systems. In a similar vein, "case-control" studies, wherein, the EHR system is introduced along with information and communication technologies (ICT) in one organization and as a standalone in another similar organization would allow a comparison of enacted EHR-in-practice, network structures, and types of knowledge activated in the two scenarios. Similarly, "longitudinal" studies, wherein the ICT is introduced after certain period of time following the launch of a new EHR system, could shed light on changes to network structures and EHR-in-practice following the introduction of the new ICT.

On a related note, the KIP framework provides a foundation for understanding how ICTs may be leveraged to enhance IT capabilities. Therefore, it may also be beneficial to conduct future studies on the use of ICTs (e.g., SKN systems) as a standalone in healthcare organizations, i.e., without them having to accompany a new or existing EHR system. More research on use of ICTs (such as the SKN Presto system) as a stand-alone, in healthcare organizations could shed light on associations between types of ICTs, network structures and the types of knowledge activated/exchanged, and thereby serve to contribute to the literature on IT and innovation implementation in healthcare organizations.

\section{Conclusion}

The primary value of the integrated TIP/KIP framework lies in providing insight into causes of UACs of implementing EHRs, and strategies to overcome them. In effect, the broad project proposal, would not only help test the applicability of the framework to a real-world healthcare context, but also add to the body of "evidence-based management" literature in regard to communication and knowledge sharing structures that are most effective for successful implementation of EHRs, 
and at a broader level, for the implementation and sustainability of change and innovation hospitals and health systems. Therefore, future research along these lines would serve the additional purpose developing a comprehensive set of evidence-based management strategies for successful EHR implementation and “meaningful use” of EHR technology.

\section{References}

[1] American Hospital Association. HIT Incentive Payment Program: Definition of 'Meaningful Use. February 11, 2011. Available from: http://www.aha.org/content/00-10/10-ib-def-meaning-use.pdf

[2] Chaudhry B, Wang J, Wu SY, Maglione M, Mojica W, Roth E., et al. Systematic review: impact of health information technology on quality, efficiency, and costs of medical care. Annals of Internal Medicine. 2006; 144(10): 742-52. PMid: 16702590. http://dx.doi.org/10.7326/0003-4819-144-10-200605160-00125

[3] Karsh, B.T. Clinical practice improvement and redesign: how change in workflow can be supported by clinical decision support. AHRQ Publication No. 09-0054-EF. Rockville, MD: Agency for Healthcare Research and Quality. June 2009.

[4] Lau F, Price M, Boyd J, Partridge, C., Bell, H., Raworth, R. Impact of electronic medical record on physician practice in office settings: a systematic review. BMC Medical Informatics \& Decision Making. 2012; 12: 10. http://dx.doi.org/10.1186/1472-6947-12-10

[5] Healthit.Gov. February 10, 2014. Available from: http://www.healthit.gov/unintended-consequences/content/assess-problem.html

[6] Ash, J., Berg, M., Coiera, E. Unintended Consequences of IT in Health Care, Journal of the American Medical Informatics Association. 2004; 11(2): 104-112. PMid: 14633936. http://dx.doi.org/10.1197/jamia.M1471

[7] Ash, K., Stavri, C., Kuperman, G. A Consensus Statement on Considerations for a Successful CPOE Implementation. Journal of the American Medical Informatics Association. 2003; 10(3): 229-234. PMid: 12626376. http://dx.doi.org/10.1197/jamia.M1204

[8] Campbell, E., Sittig, D., Ash, J, Guappone, K., Dykstra, R. Types of Unintended Consequences Related to Computerized Provider Order Entry. Journal of the American Medical Informatics Association. 2006; 13(5): 547-556. PMid: 16799128. http://dx.doi.org/10.1197/jamia.M2042

[9] Harrison, M., Koppel, R., Bar-Lev, S. Unintended Consequences of Information Technologies in Health Care-An Interactive Sociotechnical Analysis. Journal of the American Medical Informatics Association. 2007; 14(5): 542-549. PMid: 17600093. http://dx.doi.org/10.1197/jamia.M2384

[10] Jimison H, Gorman P, Woods S, Nygren P, Walker M., Hersh W. Barriers and Drivers of Health Information Technology Use for the Elderly, Chronically Ill, and Underserved. Evidence Report/Technology Assessment No. 175. AHRQ Publication No. 09-E004. Rockville, (MD): Agency for Healthcare Research and Quality. 2008.

[11] Rollins, Genna. Unintended Consequences: Identifying and Mitigating Unanticipated Issues in EHR Use. Journal of AHIMA. January 2012; 83(1): 28-32. PMid: 22375477.

[12] Jones, SS., Koppel, R., Ridgely, MS., Palen, TE., Wu, S., Harrison, MI. Guide to Reducing Unintended Consequences of Electronic Health Records. Prepared by RAND Corporation under Contract No. HHSA290200600017I, Task Order \#5. Agency for Healthcare Research and Quality (AHRQ). Rockville, MD. August, 2011. Available from: www.ucguide.org.

[13] Mair FS, May C, O'Donnell C, Finch T., Murray E. Factors that promote or inhibit the implementation of e-health systems: an explanatory systematic review. Bulletin of the World Health Organization. 2012; 90(5): 357-64. PMid: 22589569. http://dx.doi.org/10.2471/BLT.11.099424

[14] McGinn CA, Grenier S, Duplantie J, Shaw N, Sicotte C., Mathieu, L, et al. Comparison of user groups' perspectives of barriers and facilitators to implementing electronic health records: a systematic review. BMC Medicine. 2011; 9: 46. PMid: 21524315. http://dx.doi.org/10.1186/1741-7015-9-46

[15] Tang PC, Ash JS, Bates DW, Overhage JM, Sands DZ. Personal health records: definitions, benefits, and strategies for overcoming barriers to adoption. Journal of the American Medical Informatics Association. 2006; 13: 121-6. PMid: 16357345. http://dx.doi.org/10.1197/jamia.M2025

[16] Orlikowski, W. Using Technology and Constituting Structures: A Practice Lens for Studying Technology in Organizations. Organization Science. 2000; 11(4): 404-428. http://dx.doi.org/10.1287/orsc.11.4.404.14600

[17] Orlikowski, W., Barley, S. Technology and Institutions: What Can Research on Information Technology and Research on Organizations Learn from Each Other? Management Information Systems Quarterly. 2001; 25: 145-165. http://dx.doi.org/10.2307/3250927

[18] Orlikowski, W., Yates, J. Genre Repertoire: Examining the Structuring of Communication in Organizatons. Administrative Science Quarterly. 1994; 39(4): 541-574. http://dx.doi.org/10.2307/2393771 
[19] Anderson, A., McDaniel, R. Managing health care organizations: Professionalism meets complexity science. Health Care Management Review. 2000; 25(1): 83-92. PMid: 10710732. http://dx.doi.org/10.1097/00004010-200001000-00010

[20] Burt, R. Network Structure of Social Capital. In R. I. Sutton, Staw, B.M (Eds.), Research in Organizational Behavior, Vol. 22. Greenwich, CT: JAI Press. 2000.

[21] Hansen, M.T. The search-transfer problem: Role of weak ties in sharing knowledge across organizational units. Administrative Science Quarterly. 1999; 44(1): 82-111. http://dx.doi.org/10.2307/2667032

[22] Kovner, A., Fine, D.J., D’Aquila, R. Evidence-Based Management in Health Care. Health Administration Press: Chicago, IL. 2009.

[23] McAlearney AS, Robbins J, Kowalczyk N, et al. The role of cognitive and learning theories in supporting successful EHR system implementation training: a qualitative study. Medical Care Research \& Review. 2012; 69(3): 294-315. PMid: 22451617. http://dx.doi.org/10.1177/1077558711436348

[24] Rangachari, P. Knowledge sharing networks related to hospital quality measurement and reporting. Health Care Management Review. 2008; 33(3): 253-263. PMid: 18580305. http://dx.doi.org/10.1097/01.HMR.0000324910.26896.91

[25] Rangachari, P. Knowledge sharing and organizational learning in the context of hospital infection prevention. Quality Management in Health Care. 2010; 19(1): 34-45. PMid: 20042932. http://dx.doi.org/10.1097/QMH.0b013e3181ccbd1d

[26] Rangachari, P. Madaio, M., Rethemeyer, R.K., Wagner, P., Hall, L., Roy, S., et al. The evolution of knowledge exchanges enabling successful practice change in two intensive care units. Health Care Management Review; published-ahead-of-print. Oct 22, 2013. PMid: 24153028.

[27] Rangachari, P., Madaio, M., Rethemeyer, R.K., Wagner, P., Hall, L., Roy, S., et al. Cumulative impact of top-down periodic quality improvement communications on infection prevention practices \& outcomes in two units. Health Care Management Review, published-ahead-of-print. Aug 12, 2014. PMid: 25120195.

[28] Barrett, M. Information Technology, Organizational Change, and New Modes of Organizing. In A. Salazar; Sawyer, S (Ed.). Handbook of Information Technology in Organizations and Electronic Markets. Singapore: World Scientific Publishing. 2007. http://dx.doi.org/10.1142/9789812707628_0003

[29] Burgnoon, J., Bonito, J., Bengtson, B., Ramirez, A. Testing the Interactivity Model: Communication Processes, Partner Assessments and the Quality of Collaborative Work. Journal of Management Information Systems. 2000; 16(3): 33-56.

[30] Lobach D, Sanders GD, Bright TJ, et al. Enabling Health Care Decision-making through Clinical Decision Support and Knowledge Management. Evidence Report No. 203. AHRQ Publication No. 12-E001-EF. Rockville (MD): Agency for Healthcare Research and Quality. September, 2012.

[31] Qureshi, S., Keen, P. Organizational Transformation by Activating Knowledge: The Medicating Role of Collaborative Technologies. In A. Salazar; Sawyer, S (Ed.). Handbook of Information Technology in Organizations and Electronic Markets. Singapore: World Scientific Publishing. 2007. http://dx.doi.org/10.1142/9789812707628_0010

[32] Robey, D., Khoo, H., Powers, C. Situated Learning in Cross-Functional Virtual Teams. IEEE Transactions on Professional Communications. 2000; 42(1): 51-66. http://dx.doi.org/10.1109/47.826416

[33] Rangachari, P. Overcoming the unintended adverse consequences of implementing health IT through human resource and knowledge management. In J. D. Blair, M. D. Fottler, \& G. T. Savage (Eds.), Strategic Human Resource Management in Health Care, Advances in Health Care Management. Bingley, UK: Emerald. 2010; 9: 163-194.

[34] Aspden, P. Wolcott, J., Bootman, J.L., Cronenwett, L.R. (Eds) Preventing Medication Errors: Quality Chasm Series, National Academies Press: Washington, DC. 2007.

[35] IOM. Institute of Medicine. To Err is Human: Building a Safer Health System. National Academy Press Washington, DC. 1999.

[36] Black AD, Car J, Pagliari C, et al. The impact of eHealth on the quality and safety of health care: a systematic overview. PLoS Medicine. 2011; 8(1): e1000387. PMid: 21267058. http://dx.doi.org/10.1371/journal.pmed.1000387

[37] McKibbon KA, Lokker C, Handler SM, et al. Enabling Medication Management Through Health Information Technology. Evidence Report/Technology Assessment No. 201. AHRQ Publication No. 11-E008-EF. Rockville (MD): Agency for Healthcare Research and Quality. 2011.

[38] McKibbon KA, Lokker C, Handler SM, et al. The effectiveness of integrated health information technologies across the phases of medication management: a systematic review of randomized controlled trials. Journal of the American Medical Informatics Association. 2012; 19(1): 22-30. PMid: 21852412. http://dx.doi.org/10.1136/amiajnl-2011-000304

[39] ALA Tech Source. Inmagic Helps Organizations Build Social Knowledge Networks with Presto. September 1, 2010. Available from: http://www.librarytechnology.org/ltg-displaytext.pl?RC=14002

[40] Information Today. Inmagic Presto Strengthens Social Knowledge Network Capabilities. August 30, 2010. Available from: http://newsbreaks.infotoday.com/Digest/Inmagic-Presto--Strengthens-Social-Knowledge-Network-Capabilities-65913.asp 